\title{
Screening of cognitive impairment in patients with Parkinson's disease: diagnostic validity of the Brazilian versions of the Montreal Cognitive Assessment and the Addenbrooke's Cognitive Examination-Revised
}

Rastreio de comprometimento cognitivo em pacientes com doença de Parkinson: validade diagnóstica das versões brasileiras da Montreal Cognitive Assessment e do Addenbrooke's Cognitive Examination-Revised

Emmanuelle Sobreira', Márcio A. Pena-Pereira1, Alan L. Eckeli1, Manoel A. Sobreira-Neto ${ }^{1,2}$, Marcos H. N. Chagas ${ }^{1}$, Maria P. Foss ${ }^{1}$, Brenna Cholerton ${ }^{3}$, Cyrus P. Zabetian ${ }^{4}$, Ignacio F. Mata ${ }^{4}$, Vitor Tumas ${ }^{1}$

\begin{abstract}
Objective: The aim of the present study is to examine the accuracy of the Brazilian versions of the Montreal Cognitive Assessment (MoCA) and the Addenbrooke's Cognitive Examination-Revised (ACE-R) to screen for mild cognitive impairment (PDMCl) and dementia (PDD) in patients with Parkinson's disease (PD). Method: Both scales were administered to a final convenience sample of 79 patients with PD. Patients were evaluated by a neurologist, a psychiatrist and a neuropsychologist using UPDRS, Hoehn and Yahr and Schwab and England scales, global deterioration scale, a psychiatric structured interview, Mattis Dementia Rating Scale and other cognitive tests. Results: There were 32 patients with PDMCl and 17 patients with PDD. The MoCA and the ACE-R were able to discriminate patients with PDD from the others. Conclusion: Both scales showed to be useful to screen for dementia but not for mild cognitive impairment in patients with PD.
\end{abstract}

Keywords: MoCA, ACE-R, Parkinson's disease, mild cognitive impairment, dementia, cognitive assessment, neuropsychological tests.

\section{RESUMO}

Objetivo: O objetivo do estudo foi avaliar a acurácia das versões Brasileiras das escalas: Montreal Cognitive Assessment (MoCA) e Addenbrooke's Cognitive Examination-Revised (ACE-R), no rastreamento de comprometimento cognitivo leve (CCL) e demência em pacientes com doença de Parkinson (DP). Método: As duas escalas foram aplicadas a uma amostra de conveniência de 79 pacientes com DP. Os pacientes foram avaliados por um neurologista, um psiquiatra e uma neuropsicóloga que utilizaram a UPDRS, a escala de Hoehn e Yahr, a escala de Schwab e England, a escala de deterioração global, uma entrevista psiquiátrica estruturada, a escala de demência de Mattis e outros testes cognitivos. Resultados: 32 pacientes foram diagnosticados com CCL e 17 com demência. A MoCA e o ACE-R foram capazes de discriminar pacientes com demência dos demais. Conclusão: As duas escalas se mostraram úteis para rastrear demência, mas não CCL, em pacientes com DP.

Palavras-chave: MoCA, ACE-R, doença de Parkinson, comprometimento cognitivo leve, demência, avaliação cognitiva, testes neuropsicológicos.

Cognitive impairment is a common clinical problem in the course of Parkinson's disease (PD). It is associated with decreased quality of life, increased caregiver burden, higher mortality rates, higher risk for institutionalization, and increased treatment $\operatorname{costs}^{1}$. In this way, cognitive assessment is a key factor in evaluating patients with $\mathrm{PD}$ in research or clinical settings.

There are many different methods and instruments that can be used to evaluate cognition in patients with PD. Short

'Universidade de São Paulo, Faculdade de Medicina de Ribeirão Preto, Departamento de Neurociências e Comportamento, Ribeirao Preto SP, Brazil;

${ }^{2}$ Universidade de Fortaleza, Faculdade de Medicina, Fortaleza CE, Brazil;

${ }^{3}$ University of Washington, School of Medicine, Department of Psychiatry and Behavioral Sciences, Seattle WA, USA;

4 University of Washington, School of Medicine, Department of Neurology, Seattle WA, USA.

Correspondence: Vitor Tumas; Departamento de Neurociências e Comportamento - FMRP / USP; Avenida Bandeirantes, 3900 ; 14049 -900 Ribeirão Preto SP, Brasil; E-mail:tumasv@fmrp.usp.br

Conflict of interest: There is no conflict of interest to declare.

Received 28 January 2015; Received in final form 01 July 2015; Accepted 22 July 2015. 
global cognitive scales with adequate sensitivity to screen for the presence of cognitive impairment may be useful in the context of a routine clinical evaluation but may also be relevant for use in large epidemiological studies. For this, the scales should ideally be able to identify mild cognitive impairment (MCI) and dementia as well as to follow changes in cognition over time.

The Mini-Mental Status Examination (MMSE) is possibly the most popular short cognitive scale used to assess cognition, but its accuracy in assessing patients with PD has been questioned $^{2}$. The Montreal Cognitive Assessment (MoCA) and the Addenbrooke's Cognitive Examination-Revised (ACE-R) are other brief global cognitive instruments that have been used to evaluate cognition in general population and in patients with $\mathrm{PD}^{3,4}$. Many studies reported that these scales can be useful and may be better than the MMSE to detect cognitive impairment in patients with PD $2,5,6,7,8,9,10,11,12,13,14,15$. In Brazil, the MoCA and ACE-R have been translated and adapted for clinical use, but their diagnostic validity in Brazilian clinical settings still remains uncertain ${ }^{16,17,18,19}$. Differences in formal education, prior exposure to formal testing environments, previous experience with or knowledge of specific test items (e.g., confrontational naming items), and other factors may limit the validity of a measure when applied cross-culturally. Additionally, performance on these measures may differ across patients groups due to disease-specific effects.

There are few studies on the diagnostic accuracy of the MoCA and ACE-R to detect cognitive impairment in Brazilian patients. Besides, only one of them have evaluated patients with $\mathrm{PD}^{15}$. Therefore, we aimed in this study to assess the discriminant validity of the MoCA and ACE-R measures to detect $\mathrm{MCI}$ and dementia in Brazilian patients with PD in comparison to established diagnostic criteria and a gold standard neuropsychological test battery.

\section{METHOD}

This was a cross-sectional and observational study developed over a convenience sample of 79 patients diagnosed with PD according to the United Kingdom Brain Bank diagnostic criteria that consecutively attended the movement disorders outpatient clinic of Ribeirão Preto School of Medicine from September 2009 to April $2012^{20}$.

Patients were invited to participate if they were older than 18 years old and if they spontaneously consented to participate in the study. Exclusion criteria included: obvious delirium, severe and uncontrolled hallucinations, depression, poorly controlled motor symptoms, therapeutic regimen in adjustment, in use of anticholinergic drugs. One hundred eighteen patients were initially evaluated; 39 were excluded due to being unable to complete the evaluation $(\mathrm{n}=15)$, exhibiting significant psychiatric problems $(\mathrm{n}=23)$, remained persistently in "off state" during the course of the clinical evaluation $(n=1)$. Patients were initially examined by a neurologist who evaluated them using the UPDRS, the Hoehn and Yahr scale (HY), the Schwab and England functional scale (SE), and the global deterioration scale (GDS) ${ }^{21}$. Then, they were evaluated by an experienced psychiatrist using a structured interview to measure DSM-IV Axis I psychiatric symptoms (SCID-CV). Finally, patients were also evaluated by a neuropsychologist that used the Global Deterioration Scale GDS, Mattis Dementia Rating Scale (MDRS) ${ }^{22}$, clock drawing test, phonemic verbal fluency test (FAS), semantic verbal fluency test (animals), Rey Auditory Verbal Learning Test (RAVLT), Rey-Osterreith Complex Figure Test, Color Trails Test (CTT), Stroop Color and Word Test, the MoCA and the ACE-R. The cognitive assessment was performed across two or more days, within a maximum interval of 15 days. Patients with motor fluctuations were evaluated in the "on-state". Patients with PD were classified as having normal cognition (PDNC), minimal cognitive impairment (PDMCI) or dementia (PDD) according to diagnostic criteria established by the Movement Disorder Society ${ }^{23,24}$. The diagnosis of dementia was made by consensus between the neurologist and the neuropsychologist. The diagnosis of MCI was made by the neuropsychologist considering normative data for the cognitive tests, except using the data obtained with the MoCA and the ACE-R. When using standardized scores for the interpretation of the cognitive tests, those scores below 1.5 standard deviations from the mean of published normative data were considered to represent a deficit.

The local research ethics committee approved the study and all participants or their relatives provided a signed informed consent to participate.

The data were evaluated using chi-square test and non-parametric statistics: Mann-Whitney test and the Kruskall-Wallis test with Dunn's post hoc test. We calculated the Spearman's correlation coefficients between the scores of MoCA, ACE-R and other clinical scales. The receiver operating characteristic (ROC) curves were performed in order to address the sensitivity and specificity of the MoCA and ACE-R to diagnose MCI and PDD. The statistical analysis was performed using the SPSS 19 and the level of statistical significance was defined as $\mathrm{p}<0.05$.

\section{RESULTS}

Demographic and clinical characteristics of the 79 patients with PD evaluated in this sample are listed in Table. There were 32 patients (40.4\%) diagnosed with MCI and 17 (21.5\%) diagnosed with PDD. Patients with PDD were older and had more advanced disease according to the HY scale. They also had higher UPDRS scores and lower SE scores than patients with PDNC. There were no significant differences in education level between groups. 
Table. Demographic and clinical characteristics of the sample of patients with Parkinson's disease presented by cognitive diagnosis.

\begin{tabular}{lcccc} 
& PDNC & PDMCl & PDD & P \\
\hline $\mathrm{N}$ Gender (male) & 30 & 32 & 17 & $3 / 13$ \\
\hline & $10 / 20$ & $16 / 15$ & median (min-max) & \\
\hline Age (years) & median (min-max) & median (min-max) & $72,50(53-81)^{\star}$ & 0.004 \\
Education (years) & $61(28-79)$ & $10(0-20)$ & $5.50(2-18)$ & 0.174 \\
Disease duration (months) & $4(1-20)$ & $96(24-276)$ & $114(18-140)$ & 0.376 \\
UPDRS total score & $72(24-192)$ & $33(7-59)$ & $34.5(10-89)$ & 0.027 \\
SE & $25.5(6-62) \#$ & $90(60-100)$ & $85(60-100)$ & 0.012 \\
HY & $90(60-100) \#$ & $2(0-2)$ & $2(1-4) \star$ & 0.024 \\
MoCA & $2(1-3)$ & $23(14-29)$ & $17(7-24) \star$ & 0.0001 \\
ACE-R & $23.50(15-29)$ & $80(41-98)$ & $67(32-85) \star$ & 0.0001 \\
\hline
\end{tabular}

PDNC: PD patient with normal cognition; PDMCI:PD patient with minimal cognitive impairment;PDD:PD patient with dementia; UPDRS: Unified PD Rating Scale; HY: Hoehn and Yahr scale; SE: Schwab and England functional scale; MoCA: Montreal Cognitive Assessment; ACE-R: Addenbrooke's Cognitive ExaminationRevised; *different from all; \#different from PDD.

The MoCA and the ACE-R were able to discriminate patients with PDD from the others.The area under the ROC curve for the MoCA to diagnose PDMCI was $0.50(95 \% \mathrm{CI}=0.38-0.67)$ and for the ACE-R was 0.53 $(95 \% \mathrm{CI}=0.35-0.64)$ (Figure). The best cut off score for MoCA to differentiate patients with PDNC from patients with PDMCI was 26 (scores of 25 or below indicate impairment) with a sensitivity of $84 \%$ and specificity of $27 \%$, while for the ACE-R was 89 with a sensitivity of $84 \%$ and specificity of $20 \%$. The area under the ROC curve for the MoCA to diagnose dementia was $0.86(95 \% \mathrm{CI}=0.76-0.95)$ and for the ACE-R was 0.84 (95\%CI $=0.74-0.94)$ (Figure). The best cut off score for MoCA to differentiate patients with PDD from the others was 21 , with a sensitivity of $94 \%$ and specificity of $68 \%$, while for the ACE-R was 76 with a sensitivity of $88 \%$ and specificity of $68 \%$.

The MoCA and ACE-R scores correlated significantly with MDRS scores $(p=0.0001, c c=0.71$ and $p=0.0001, c c=0.75)$, with GDS ( $\mathrm{p}=0.0001, \mathrm{cc}=-0.52$ and $\mathrm{p}=0.0001, \mathrm{cc}=0.48)$, HY ( $p=0.0001, c c=-0.40$ and $p=0.002, c c=-0.34)$, total score of the UPDRS ( $p=0.005, c c=-0.31$ and $p=0.005, c c=-0.31$ ), schooling $(p=0.007, c c=-0.29$ and $p=0.0001, c c=-0.49)$ and age $(\mathrm{p}=0.01, \mathrm{cc}=-0.28$ and $\mathrm{p}=0.01, \mathrm{cc}=-0.26)$.

\section{DISCUSSION}

Our findings showed that short global cognitive scales, as MoCA and ACE-R may be effective global instruments to be used to detect dementia in Brazilian patients with PD. However, the application of certain intermediary cut-off scores for detection of PDMCI did not demonstrate adequate accuracy in our study. In this sample of patients with PD, the scores in both global cognitive tests suggested that the performance of patients with PDMCI were more like that of patients with PDNC than from those with PDD.

These findings differ from other previous studies that showed that MoCA could be a valid and reliable tool for

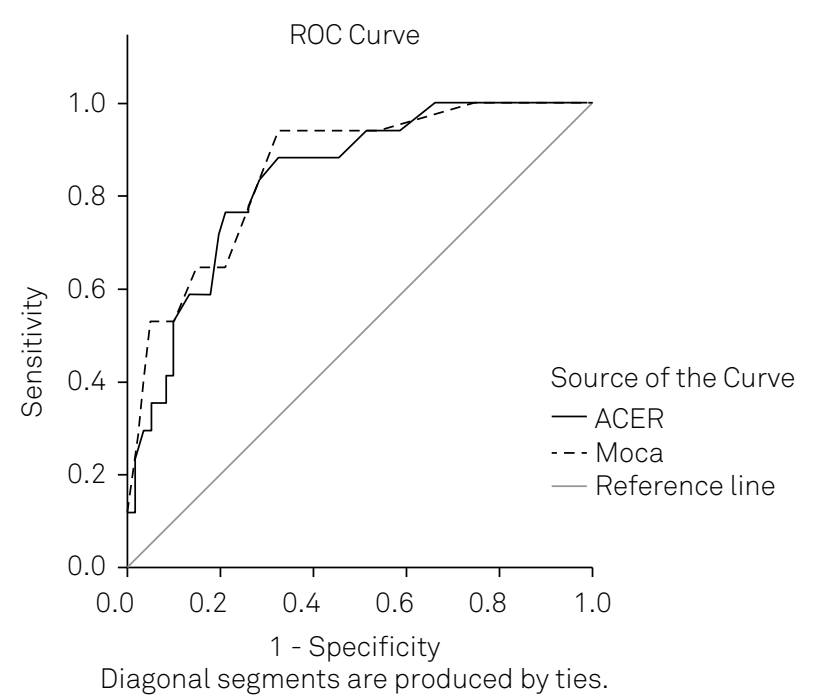

ACE-R: Addenbrooke's Cognitive Examination-Revised; MoCA: Montreal Cognitive Assessment; PDD:PD patient with dementia.

Figure. The ROC curve for the ACE-R and MoCA to discriminate patients with PDD from the others.

screening of MCI in the Brazilian population ${ }^{18,25}$. In those studies, MoCA reached good accuracy for the identification of subjects with MCI. Although in these studies the cut-off scores were similar to those obtained in our study, the accuracy was higher. This may be due to the distinct characteristics of the samples, since we evaluated only patients with $\mathrm{PD}$, and the subjects in our sample had lower educational level. There are no studies that evaluated the accuracy of the ACE-R to diagnose MCI in the Brazilian population.

On the other hand, both MoCA and ACE-R proved to be good instruments for screening of PDD. The cut-off scores and accuracy observed in our sample were very similar to those observed in other studies using theses scales in the general Brazilian population ${ }^{15,16,18,25}$.

The practical importance to study alternative short global scales to evaluate cognition in patients with PD is due to the general impression that the MMSE, the most commonly used 
instrument worldwide to evaluate cognition in patients with PD, does not provide sufficient accuracy for the detection of dementia or MCI in these patients ${ }^{2,10}$.

MoCA was developed as a brief screening instrument to diagnose MCI and dementia due to Alzheimer's disease (AD). Validation studies of culturally adapted versions of this scale showed a pattern of results similar to the original version in the screening for cognitive impairment, with better diagnostic accuracy as compared with the MMSE in the general population, and also in patients with $\mathrm{PD}^{10,12}$. The original validation data suggested that the use of a MoCA cut-off score of 26 was ideal to detect MCI. Specific studies in the Brazilian population showed that the use of the cut-off of scores of 24 or 25 points had the greater accuracy for the identification of MCI, and that the cut-off scores of 21 or 22 was ideal for the identification of dementia ${ }^{25}$. Studies in patients with PD showed similar findings with some small variations ${ }^{10,12,26}$. As we cited above, some specific characteristics of our sample, especially the lower educational level, may have reduced the accuracy of MoCA in recognizing patients with PDMCI. However, our findings confirmed that using a MoCA cut-off score of 21 could be a valid measure for screening dementia in patients with PD.

The ACE-R was developed as a brief test that would be sensitive to the early stages of dementia. The scale was adapted and studied in the Brazilian population and showed that a cut-off score $<78$ yielded high diagnostic accuracy for diagnosis of dementia ${ }^{16,19}$. That was a cut-off score far from what was observed in other studies conducted in different populations, in which the best cut-off scores were between 88 and 82. Despite this differences, the Brazilian version of the ACE-R presented similar accuracy for diagnosis of dementia. Studies using ACE-R for detection of dementia in patients with PD found variable cut-off scores but they presented with similar accuracy $^{27}$. In general, the accuracy was judged to be superior to that found with the application of the MMSE. Although some studies have shown that ACE-R may be useful for detecting MCI, studies in patients with PD found controversial findings $\mathrm{s}^{5,8,10,12,26}$. Our study showed that in our sample the best cut-off scores for the ACE-R to best discriminate patients with PDD was < 76. However, in our sample, the ACE-R did not accurately classify patients with PDMCI.

In our sample, the scores of the MoCA and ACE-R significantly correlated with schooling and age of the patients, suggesting that as was expected, these factors may play a significant role in the performance of subjects assessed by these tests. Other studies confirmed that scores in MOCA were strongly dependent of years of education. The scores of MOCA and ACE-R also correlated very well with other global measures of cognition and functionality, indicating that the Brazilian versions of these scales have good concordant validity.

In conclusion, the accuracy of both scales, MoCA and ACE-R, were very similar for screening of cognitive impairment in patients with PD. These two global scales showed good discriminative validity to identify patients with PDD, but the use of these scales to screen for PDMCI stayed away from the expected precision and sensitivity. This determines the necessity for detailed neuropsychological testing for evaluation of specific cognitive domains. Our findings also showed that the use of short global cognitive scales as MoCA and ACE-R lacks specificity to detect early cognitive changes in Brazilian patients with PD.

\section{References}

1. Emre M, Aarsland D, Brown R, Burn DJ, Duyckaerts C, Mizuno $Y$ et al. Clinical diagnostic criteria for dementia associated with Parkinson's disease. Mov Disord. 2007;22(12):1689-707; quiz 837. doi:10.1002/mds.21507

2. Zadikoff C, Fox SH, Tang-Wai DF, Thomsen T, Bie RM, Wadia P et al. A comparison of the mini mental state exam to the Montreal cognitive assessment in identifying cognitive deficits in Parkinson's disease. Mov Disord. 2008;23(2):297-9. doi:10.1002/mds.21837

3. Nasreddine ZS, Phillips NA, Bédirian V, Charbonneau S, Whitehead V, Collin I et al. The Montreal Cognitive Assessment, MoCA: a brief screening tool for mild cognitive impairment. J Am Geriatr Soc. 2005;53(4):695-9. doi:10.1111/j.1532-5415.2005.53221.x

4. Mioshi E, Dawson K, Mitchell J, Arnold R, Hodges JR. The Addenbrooke's Cognitive Examination Revised (ACE-R): a brief cognitive test battery for dementia screening. Int J Geriatr Psychiatry. 2006;21(11):1078-85. doi:10.1002/gps.1610

5. Komadina NC, Terpening Z, Huang Y, Halliday GM, Naismith SL, Lewis SJ. Utility and limitations of Addenbrooke's Cognitive Examination-Revised for detecting mild cognitive impairment in Parkinson's disease. Dement Geriatr Cogn Disord. 2011;31(5):349-57. doi:10.1159/000328165

6. Reyes MA, Lloret SP, Gerschcovich ER, Martin ME, Leiguarda $\mathrm{R}$, Merello M. Addenbrooke's Cognitive Examination validation in Parkinson's disease. Eur J Neurol. 2009;16(1):142-7. doi:10.1111/j.1468-1331.2008.02384.x

7. Larner AJ. Comparing diagnostic accuracy of cognitive screening instruments: a weighted comparison approach. Dement Geriatr Cogn Dis Extra. 2013;3(1):60-5. doi:10.1159/000348623

8. McColgan P, Evans JR, Breen DP, Mason SL, Barker RA, Williams-Gray $\mathrm{CH}$. Addenbrooke's Cognitive Examination-Revised for mild cognitive impairment in Parkinson's disease. Mov Disord. 2012;27(9):1173-7. doi:10.1002/mds.25084

9. Nazem S, Siderowf AD, Duda JE, Have TT, Colcher A, Horn SS et al. Montreal cognitive assessment performance in patients with Parkinson's disease with "normal" global cognition according to mini-mental state examination score. J Am Geriatr Soc. 2009;57(2):304-8. doi:10.1111/j.1532-5415.2008.02096.x

10. Hoops S, Nazem S, Siderowf AD, Duda JE, Xie SX, Stern MB et al. Validity of the MoCA and MMSE in the detection of $\mathrm{MCl}$ and dementia in Parkinson disease. Neurology. 2009;73(21):1738-45. doi:10.1212/WNL.0b013e3181c34b47

11. Gill DJ, Freshman A, Blender JA, Ravina B. The Montreal cognitive assessment as a screening tool for cognitive impairment in Parkinson's disease. Mov Disord. 2008;23(7):1043-6. doi:10.1002/mds. 22017 
12. Dalrymple-Alford JC, MacAskill MR, Nakas CT, Livingston L, Graham C, Crucian GP et al. The MoCA: well-suited screen for cognitive impairment in Parkinson disease. Neurology. 2010;75(19):1717-25. doi:10.1212/WNL.0b013e3181fc29c9

13. Chou KL, Amick MM, Brandt J, Camicioli R, Frei K, Gitelman D et al. A recommended scale for cognitive screening in clinical trials of Parkinson's disease. Mov Disord. 2010;25(15):2501-7. doi:10.1002/mds.23362

14. Chou KL, Lenhart A, Koeppe RA, Bohnen NI. Abnormal MoCA and normal range MMSE scores in Parkinson disease without dementia: cognitive and neurochemical correlates.. Parkinsonism Relat Disord. 2014;20(10):1076-80. doi:10.1016/j.parkreldis.2014.07.008

15. Rocha MSG, Bassetti EM, Oliveira MO, Kuark RGB, Estevam NM, Brucki SMD. Addenbrooke's Cognitive Examination-Revised is accurate for detecting dementia in Parkinson's disease patients with low educational level. Dement Neuropsychol. 2014;8(1):20-5.

16. Carvalho VA, Barbosa MT, Caramelli P. Brazilian version of the Addenbrooke Cognitive Examination-revised in the diagnosis of mild Alzheimer disease. Cogn Behav Neurol. 2010;23(1):8-13. doi:10.1097/WNN.0b013e3181c5e2e5

17. Sarmento, A. L. R. Apresentação E Aplicabilidade Da Versão Brasileira Da Moca (Montreal Cognitive Assessment) Para Rastreio De Comprometimento Cognitivo Leve [MD]. 2009, Programa De PósGraduação, Escola Paulista De Medicina Da Universidade Federal De São Paulo, São Paulo (SP).

18. Memória CM, Yassuda MS, Nakano EY, Forlenza OV. Brief screening for mild cognitive impairment: validation of the Brazilian version of the Montreal cognitive assessment. Int J Geriatr Psychiatry. 2013;28(1):34-40. doi:10.1002/gps.3787

19. Amaral-Carvalho V, Caramelli P. Normative data for healthy middle-aged and elderly performance on the Addenbrooke Cognitive Examination-Revised. Cogn Behav Neurol. 2012;25(2):72-6. doi:10.1097/WNN.0b013e318259594b

20. Hughes AJ, Ben-Shlomo Y, Daniel SE, Lees AJ. What features improve the accuracy of clinical diagnosis in Parkinson's disease: a clinicopathologic study. Neurology. 1992;42(6):1142-6. doi:10.1212/WNL.42.6.1142

21. Reisberg B, Ferris SH, de Leon MJ, Crook T. The Global Deterioration Scale for assessment of primary degenerative dementia. Am J Psychiatry. 1982;139(9):1136-9. doi:10.1176/ajp.139.9.1136

22. Foss MP, Vale FA, Speciali JG. [Influence of education on the neuropsychological assessment of the elderly: application and analysis of the results from the Mattis Dementia Rating Scale (MDRS)]. Arq Neuropsiquiatr. 2005;63(1):119-26. Portuguese. doi:10.1590/S0004-282X2005000100022

23. Dubois B, Burn D, Goetz C, Aarsland D, Brown RG, Broe GA et al. Diagnostic procedures for Parkinson's disease dementia: recommendations from the movement disorder society task force. Mov Disord. 2007;22(16):2314-24. doi:10.1002/mds.21844

24. Litvan I, Goldman JG, Tröster Al, Schmand BA, Weintraub D, Petersen RC et al. Diagnostic criteria for mild cognitive impairment in Parkinson's disease: Movement Disorder Society Task Force guidelines. Mov Disord. 2012;27(3):349-56. doi:10.1002/mds.24893

25. Martinelli JE, Cecato JF, Bartholomeu D, Montiel JM. Comparison of the diagnostic accuracy of neuropsychological tests in differentiating Alzheimer's disease from mild cognitive impairment: can the montreal cognitive assessment be better than the cambridge cognitive examination? Dement Geriatr Cogn Dis Extra. 2014;4(2):113-21. doi:10.1159/000360279

26. Ozdilek B, Kenangil G. Validation of the Turkish Version of the Montreal Cognitive Assessment Scale (MoCA-TR) in patients with Parkinson's disease. Clin Neuropsychol. 2014;28(2):333-43. doi:10.1080/13854046.2014.881554

27. Kaszás B, Kovács N, Balás I, Kállai J, Aschermann Z, Kerekes Z et al. Sensitivity and specificity of Addenbrooke's Cognitive Examination, Mattis Dementia Rating Scale, Frontal Assessment Battery and Mini Mental State Examination for diagnosing dementia in Parkinson's disease. Parkinsonism Relat Disord. 2012;18(5):553-6. doi:10.1016/j.parkreldis.2012.02.010 